\title{
Negotiating the Unknown: The Role of Uncertainty in Social Exchange
}

Scott V. Savage ${ }^{1 *}$ and Kelly Bergstrand ${ }^{2}$

${ }^{1}$ Department of Sociology, University of California, Riverside

${ }^{2}$ Department of Sociology, University of Arizona

\section{Abstract}

This article documents the role of uncertainty in social exchange. Specifically, it reviews how social exchange theorists incorporate uncertainty when explaining psychological processes and social behaviors. After identifying and examining the structural roots of uncertainty, the article addresses how uncertainty affects actor behavior and attitude formation, from curbing power use to promoting the development of more committed, trusting and cohesive exchange partnerships. By assessing the consequences of uncertainty and risk for social exchange, this article contributes to sociological knowledge about the nature and form of relationships in an uncertain world.

Every day people participate in a series of social exchanges-from negotiating contracts with business associates to giving gifts in celebration of a birthday. Rarely do these exchanges involve perfect information about the social structures that frame them or the behaviors of exchange partners. People, then, often have to assess the behaviors and motivations of others using limited information and make choices without knowing with certainty the consequences of those choices. That is, humans overcome the paralyzing effects of "not knowing" to take action in an uncertain world.

Even more curious is the fact that they often do this in consistent and predictable ways. Social psychologists have studied these patterned behaviors and have posited numerous theories to account for the attitudes and actions of individuals in uncertain social environments (Hogg 2006; Molm et al. 2009; Robinson and Smith-Lovin 2006). One line of social psychological inquiry that considers uncertainty when offering theoretical explanations for human behavior is social exchange. ${ }^{1}$

Social exchange is a social psychological perspective or orienting strategy that assumes many social interactions exist as exchanges of valued social and material resources between actors (Homans 1974; Thibaut and Kelley 1959) and that opportunity structures shape these exchanges (Molm 2006). Exchange theorists use these meta-theoretical assumptions to craft theoretical arguments about human behavior and psychology. Many of these theories recognize either explicitly or implicitly that the process of exchange is by nature uncertain: individuals do not know what the outcome of an exchange will be or whether the outcome will be advantageous or disadvantageous. Uncertainty (and the risk that follows from it), then, is an important element in exchange-based explanations of interaction, trust, and relational cohesion.

In this article we review these arguments, and in the process, make two contributions. First, we identify the sources of uncertainty in social exchange. Second, we offer a systematic account of how uncertainty shapes the way we exchange with others and how these exchanges affect the integrative bonds that develop between pairs of actors. That is, we document in one coherent article how uncertainty informs numerous social exchange Both authors are contributed equally. 
theories by delineating the structural sources of uncertainty as well as the effects of uncertainty in the exchange process.

\section{Social exchange}

Social exchange starts with the idea that for humans to get what they need and value, they have to exchange with others. It focuses on those aspects of social life concerning the "benefits that people obtain from, and contribute to, social interaction and the opportunity structures and interdependences that govern those exchanges" (Molm 2006, p. 24). This emphasis on social structure and sustained relationships distinguishes it from both neo-classical economics and behavioral psychology and allows for the development of unique theoretical insights into social life.

The basic elements of social exchange are the actors who exchange, the resources exchanged, the structures within which exchange relations develop, the form of exchange, and the process of exchange (Molm 2003). Social exchange theory adopts a minimalist view of the actor (Lawler et al. 1993). Actors, either individuals or collectives, are assumed to be self-interested and motivated to behave in ways that increase valued benefits and decrease negatively valued outcomes. Whether these behaviors are prompted by forethought or hindsight is a point of contention. Some social exchange theorists assume rational actors who make calculated choices in an effort to maximize their attainment of valued resources (e.g., Bienenstock and Bonacich 1993; Willer 1999). Others contend that actors learn from past action and modify their behaviors accordingly (e.g., Emerson 1972a).

Resources in social exchange are capabilities or objects that are held by one actor and valued by another actor in an exchange relation. Resources then can be almost anything, from tangible goods or services to benefits such as status, approval, advice, or psychological gratification. A skill or object may be valued by some actors and not by others, so whether the skill or object is a resource depends on the actors engaging in the exchange relation.

An actor's ability to secure resources is in part a function of the exchange structure. Exchange structures bound the mutual dependence of actors and vary by network structure and exchange form. Network structures shape, to a great degree, the exchange behaviors of actors as they affect the availability of alternative exchange partners. In Power-Dependence Theory (Emerson 1962, 1972b), having alternative exchange partners decreases one's dependence on a single actor for resources, and if the alternatives do not have alternatives of their own, creates a power advantage in that one's exchange partners are more dependent on her then she is on them. In Network Exchange Theory (NET), a relation is an exchange opportunity between a pair of decision-making actors, an actor's position is designated by its pattern of relations to other actors, and a network is a set of positions and relations that forms a unitary structure (Markovsky et al. 1993; Willer 1999). In both theories, the structure of the network has ramifications for an actor's ability to acquire desired resources.

What these ramifications are, however, depend on the type of connections linking network actors. Power-Dependence Theory distinguishes between positively and negatively connected networks. Positively connected relations exist when exchange in one relation increases exchange in another; exchange relations are negatively connected when exchange in one decreases exchange in the other (Molm 1997). NET identifies three types of connections: exclusive, inclusive, and null. Exclusive connections are similar to negatively connected exchange networks in that an actor may exchange with one 
exchange partner on any particular exchange opportunity. Inclusive connections exist when an actor must exchange with all of his exchange partners in order to complete an exchange. Null connections are those where an actor can exchange with all of her exchange partners or just one of them (Willer 1999). Although these two theories present slightly different conceptions of network connections, they agree that these connections are critical for understanding how different network shapes affect exchange behavior, as they affect how dependent any actor is on any other actor for resources in Power-Dependence Theory (Emerson 1972a,b) and how likely any actor is to be excluded from 2 exchange in NET (Willer 1999).

Another component of the exchange structure is the form of exchange, which includes direct exchanges, generalized exchanges, and productive exchanges. In direct exchange between two actors, each actor's outcomes depend directly on another actor's behaviors. There are two types of direct exchange, which we will discuss later. In generalized exchange, which requires three or more actors, each actor gives to another and while no two actors directly reciprocate, all actors receive through indirect reciprocation. In productive exchange, two or more actors work together to produce a joint good that would not have been possible without the input of all actors, such as coauthoring a paper. Like network structures, these different forms of exchange bound the dependence of actors and the exchange experience.

The process of exchange refers to the interactions that occur within exchange structures. Exchange opportunities are all instances in which actors can initiate an exchange by making an offer or giving a resource. When offers or gifts result in the mutual exchange of benefits, a transaction occurs, with repeated transactions between the same actors resulting in an exchange relation.

Theories of social exchange use these elements to explain human psychology and behavior. In the pages that follow, we review how variations in these elements affect the uncertainty associated with exchange and the ramifications of this for social interaction. But first, we define uncertainty.

\section{Uncertainty in social exchange}

There is a tendency for social exchange theorists to treat uncertainty and risk as interchangeable concepts. Yamagishi et al. (1998, p. 170) for example, define social uncertainty as "the risk of being exploited in social interactions" and conceptualize uncertainty in terms of an actor not knowing whether exchange partners will succumb to incentives and act in ways that disadvantage the actor. Similarly, Kollock (1994) assesses how uncertainty in the form of "information asymmetries," in which some parties of the exchange have more information than others, can leave a participant in exchange vulnerable to exploitation. Another common way of conceptualizing uncertainty concerns the risk of not finding someone with whom to exchange (Cook and Emerson 1978; Markovsky et al. 1993). Those adopting this perspective define uncertainty as "the subjective probability of concluding a satisfactory transaction with any partner" (Cook and Emerson 1984 , p. 13). This propensity to conflate uncertainty and risk stems from the reality that risky situations are by nature uncertain (Molm et al. 2009).

Still, uncertainty and risk are conceptually distinct (Molm et al. 2009). Uncertainty can be conceived of broadly as simply not knowing what might follow from a particular exchange action, while risk goes beyond this and involves the possibility of future exchange behaviors resulting in the loss of benefits. Some uncertain situations may be deemed more risky than others. In the pages that follow, we review the role of 
uncertainty in the social exchange literature, paying particular attention to the relationship between uncertainty and risk and the behavioral and psychological consequences of both in social exchange. Before we do this, however, we first identify those aspects of exchange that introduce uncertainty and risk into the exchange process.

\section{Sources of uncertainty and risk}

All exchanges are uncertain, as actors never know a priori the intentions of exchange partners or what they will receive from an exchange relation (Lawler and Ford 1995). Still, the level of uncertainty in any particular exchange relation can vary. There are multiple sources of uncertainty in the exchange process. Exchange relations can be more or less uncertain and more or less risky depending on the nature of resources exchanged, the frequency of exchange, the structure of exchange, and the form of exchange. While various articles point to these sources of uncertainty in exchange, to our knowledge none have endeavored to delineate the multiple sources of uncertainty in one article. We now synthesize this disparate research in an attempt to identify how uncertainty is generated in processes of exchange.

Resources lie at the heart of exchange relationships, and they can affect perceptions of uncertainty. Kollock (1994), for example, varied uncertainty by altering information about the quality of the goods being exchanged; for some experimental conditions the quality of the goods was public knowledge and for others buyers did not know the quality of the goods until after the purchase was finalized. The fact that some goods could potentially be of lower value than anticipated introduced risk by allowing for the possibility of exploitation. Further, Schaefer (2009) discusses how the duplicability and transferability of resources affect uncertainty in exchange. A duplicable resource can be exchanged multiple times, such as a recipe, and its continued availability reduces uncertainty by allowing exchange to occur among multiple partners without necessitating exclusion. A transferable resource permits recipients to exchange the resource at a later time. Transferable resources, particularly when also duplicable resources, can increase uncertainty; in a network of multiple partners, giving others a duplicable resource that they themselves can exchange increases uncertainty about who will get the opportunity to exchange this resource with new partners. Yet another way information about resources can introduce either more or less uncertainty into the exchange relation is if actors know what others receive from exchange (Cook and Emerson 1978). Not all social exchange experiments provide this information, and as we will discuss later, this can affect exchange behaviors and actors' attitudes about the exchange process.

While economic exchanges assume independent, discrete transactions, social exchange assumes that actors engage in recurring, interdependent exchanges with specific partners or positions over time, leading to relatively enduring relations between actors (Molm 2003). Repeated exchange permits actors to influence their partners' behaviors and provides insight into the behavioral patterns of exchange partners. Both of these factors reduce the uncertainty associated with exchange, but they do not erase it.

In addition to resources and exchange frequency, exchange theorists recognize that network structures affect perceptions of uncertainty (Cook and Emerson 1984; Rice 2002). In a network, two exchange relations are connected if they share a focal actor and if exchange in one relation impacts exchange in the other. As we previously mentioned, Power-Dependence theorists identify two different types of connections: positive and negative. The competitive nature of negatively connected exchange networks augments uncertainty as actors are less confident that they will be able to find an exchange partner 
on any particular exchange opportunity. This is not the case for positively connected exchange relations as positive connections by nature produce high exchange frequencies (Schaefer and Kornienko 2009). NET theorists also consider connection types, arguing that exclusion is primarily a concern in exclusively connected networks (Willer 1999). Actors in pure inclusively connected and null connected networks are never structurally blocked from making an exchange and thus, should be more confident in their ability to complete an exchange successfully. While this observation does not elicit the notion of uncertainty explicitly, it does suggest that at least initially actors will be more uncertain about the resolution of any particular exchange opportunity. ${ }^{2}$ Uncertainty, then, appears to be highest when network connections undermine actors' ability to successfully complete an exchange.

Types of connections alone, however, do not fully account for exchange outcomes. Their effects on exchange processes also depend on the shape of the network. PowerDependence Theory claims that exchange networks affect how dependent any one actor is on any other actor for resources or rewards. Reward power is an attribute of exchange relations and a function of each actor's dependence on the other for resources (Emerson 1962; Thibaut and Kelley 1959). Different network structures determine how dependent any actor is on any other actor for resources and as a result, the objective probabilities that an actor will participate in exchange. These objective probabilities, in turn, inform actors' "subjective probabilities of concluding a satisfactory transaction with any partner" (Cook and Emerson 1984, p. 13), thereby making a successful exchange seem more or less uncertain.

NET also recognizes that network shape and connection type combine to structure the exchange experience. For instance, the shape of an exclusively connected negotiation network determines whether any network position "is assured of being able to exclude another without cost" (Markovsky et al. 1993, p. 202). That is, the shape of the network affects the likelihood of any given actor being excluded from exchange. This is an important point, because as Lovaglia et al. (1995) note, an actor will rely on the number of direct ties to create expectations about her ability to reach successful negotiations in exclusively connected networks. Results from a study by Lucas et al. (2001), however, show that the outcomes of exchange in exclusively connected line networks become increasingly sensitive to idiosyncratic behaviors as networks expand in length, suggesting that exchange outcomes become more uncertain as exchange networks grow.

Not all power is so structurally determined: coercive power or punishment power is strategic power and concerns the extent to which one actor depends on another for avoiding punishment (Molm 1997). Although both forms of power involve uncertainty, as actors cannot know how exchange partners will respond to its use, certain aspects of coercive power make it appear more risky. Research in behavioral economics has demonstrated that people tend to treat losses and gains differently, with individuals taking greater risks to avoid losses than to acquire gains (Kahneman et al. 1991; Tversky and Kahneman 1981, 1991). Because coercive power concerns losing benefits, its use is exacerbated by greater perceptions of risk (Molm 1997). Thus, the uncertainty that accompanies power use varies across these two types of power, with coercive power being perceived as both uncertain and risky.

The exchanges that occur within network structures can take multiple forms, and these too can affect uncertainty. The two direct forms of exchange are negotiated and reciprocal exchange. Negotiated exchanges involve actors bargaining over the terms of an agreement, while reciprocal exchange is more akin to gift giving as one actor gives to another without knowing whether or when the other will return the favor. Both forms of direct 
exchange entail uncertainty. For negotiated exchange, there is uncertainty about the utility of particular bargaining tactics and the likelihood of reaching agreement with exchange partners (Cheshire et al. 2010; Molm et al. 2000). Additionally, even when both actors agree on the terms of the exchange, there is some risk that other parties will not honor the agreement if that agreement is non-binding. Overall, however, negotiated exchange tends to involve less uncertainty than reciprocal exchange, particularly if the actors make binding negotiated agreements that obligate them to fulfill the terms of those agreements. This is because both actors are involved in the negotiation of the terms of the exchange, and therefore know specific information about who will receive what and when; thus, the "joint decision making of negotiated exchange reduces uncertainty, which in turn reduces risk" (Molm 1994; p.168). In reciprocal exchange, the terms of the exchange are not overtly debated by the two interactants. Moreover, reciprocal exchange is rarely couched in legally binding terms, introducing uncertainty about when, or if, a gift will be reciprocated. "Consequently, actors in reciprocal exchange relations risk giving benefits unilaterally while receiving little or no return" (Molm et al. 2000, p. 1401).

The two indirect forms of exchange are productive and generalized. In productive exchange, two or more actors must work together to produce a joint good for either to obtain benefits; an example is dancing the tango, which necessitates that both actors contribute to the end result and where it is not possible for one actor to benefit without the input of the other (Lawler 2001; Lawler et al. 2000; Molm 1997). While there is some uncertainty that the other actors will not contribute their fair share to the task, the actors have limited opportunities to take advantage of each other since both must work together to achieve the good. Additionally, because each actor is contributing, he or she has some sense of the quality and form of the final product. In generalized exchange individuals give to someone without directly expecting anything in return. The nature of this form of exchange creates the most uncertainty as people may not know when, if ever, they will receive a benefit from the exchange or what exactly the benefit might be. An example is strangers assisting people whose cars have broken down; directly helping someone does not guarantee personal assistance at a later time but contributes to a system in which most individuals receiving aid in vehicular emergencies. Generalized exchange can be chain-based -where A provides a resource to B, B to C, and C to A - or net based, where individual actors contribute to the group, such as by building a school, and then partake in the collective benefits (Das and Tang 2002; Ekeh 1974; Yamagishi and Cook 1993). Das and Tang (2002) argue that chain generalized exchange has a higher degree of uncertainty than net generalized exchange since net generalized exchange involves a group product, making it more likely that the group is monitoring the input and redistribution of resources.

Thus, the different aspects of the basic elements of exchange introduce varying amounts of uncertainty into social exchange. This is no small matter, as uncertainty has been shown to shape not just what actors do but how they perceive and interpret social situations and exchange relationships. We now review these effects.

\section{Effects of uncertainty}

All social exchange theories assume self-interested actors, and many assume that these actors are 'boundedly rational' insofar as they use available information to inform exchange behaviors (Lawler and Ford 1995). Limited information, however, implies uncertainty and extant literature documents, sometimes implicitly, how this impacts 
perceptions and behaviors in exchange. In particular, uncertainty has been shown to affect power use, commitment, trust, and relational cohesion in exchange relations.

Much of the early social exchange research focused on power and power use. Emerson's $(1962,1972 b)$ classic statement on power dependence described how structural conditions affect the use of reward power. Cook and Emerson (1978) tested this theory using a laboratory experiment. They find that, in line with the theory, actors in power advantaged positions use this advantage to extract maximum benefits from their exchange partners when they are unaware of the benefits that exchange partners receive, but that power use is curbed when actors are made aware of the distribution of rewards. Implicitly, this study identifies one behavioral consequence of uncertainty: power use is greater when actors are unable to compare their benefits. Ostensibly, having complete information about the distribution of benefits evokes equity norms that depress use of structural power in exchange networks.

Research in the NET tradition also finds a relationship between information and equity norms. Lovaglia et al. note that when trying to develop a restricted information setting to test a theoretical advance, they "struggled with the powerful effects of subjects' equity concerns when they felt they were receiving less than a partner who in other ways was their status equal"' (1995, p. 184). In fact, the belief among actors that they might be earning less than their partners led some actors to refuse to exchange in almost all the trials, thereby preventing the development of the predicted equilibrium and the ability to test the theory. Uncertainty about the fairness of exchange, then, can motivate behaviors that defy rational responses to structural pressures.

Uncertainty also matters for the use of coercive power. Both Molm (1997) and Lawler et al. (1988) acknowledge the risk associated with coercive power and describe how this can affect its use. Molm investigates coercive power in reciprocal exchange and finds that, despite coercion being a tool that disadvantaged actors can use to level the playing field, it is generally avoided because of the risk involved. The consequences of using coercive power are uncertain, and actors are reluctant to use it out of fear that exchange partners will retaliate with coercive tactics of their own, causing potential losses to the actor.

Lawler et al. (1988) investigate coercive tactics in the bargaining context. They find that under equal power, punitive tactics will become less frequent as coercive capability increases. They also find that under conditions of unequal power, the frequency of coercive tactics increases. Two cognitive mechanisms explain these behaviors: fear of retaliation and expectation of attack. Essentially, actors try to predict how exchange partners will respond to a punitive tactic as well as whether exchange partners are likely to initiate punitive tactics on their own. Uncertainty here is implied; while actors cannot know how their partners will behave, they rely on available information to make a best guess and then act accordingly.

Willer's (1999) work on coercive relations in NET also investigates coercion in a bargaining context. He argues that the conditions of the coercive relation and the structure affect power use. Interestingly, in null connected coercive power structures, he finds that the risk associated with the threat of loss can be enough to allow coercers to extract benefits from their exchange partners without having to actually use negative sanctions. This suggests that at least for these structures, loss aversion can prompt compliant behavior.

Uncertainty about the likelihood of making an agreement and of being exploited also affects exchange behaviors. One route for mitigating these uncertainties is the formation of committed exchange relationships, in the hope that such committed relations will increase the perceived certainty of more successful, or fair, exchange transactions. Behavioral commitment refers to the degree to which pairs of actors exchange repeatedly with 
each other rather than with alternative partners (Molm 2006). Several studies document the effect of uncertainty on commitment. Cook and Emerson (1984), for example, find that increased uncertainty regarding the perceived likelihood of concluding a satisfactory exchange transaction results in higher levels of commitment among particular exchange partners. Kollock's (1994) work also displays the close relationship between uncertainty and commitment, but unlike Cook and Emerson, he focuses on uncertainty about the quality of goods being exchanged. He finds that in the condition with less information about the quality of goods, and thus greater uncertainty, exchange partners become more committed, supporting the prediction that buyers use commitment as a method for mitigating risk in exchange. Yamagishi et al. (1998) conducted a similar study in which sellers could not only lie about the quality of the goods being sold but could also extort money from the buyers, thus creating the potential for significant losses for buyers in the exchange relation and creating a high level of uncertainty for those who could be extorted. They, too, found that more uncertainty, either from not knowing the probability of a loss or the size of the loss, resulted in higher levels of commitment. These studies demonstrate that participants gain benefits - such as avoiding exploitation and successfully completing transactions - from committed relations in situations of uncertainty.

Such commitments, however, come at a cost. When actors form committed relationships, they forego potentially advantageous exchange relationships with other partners. In both Kollock's (1994) and Yamagishi et al.'s (1998) studies, even though participants could potentially receive more benefits by negotiating with unknown partners, actors were unwilling to leave the safety of their committed relationships. Thus, increasing uncertainty in exchange structures can lead actors to join more committed relationships in an effort to reduce unknowns, although this comes with the potential cost of lost exchange opportunities with other partners.

Beyond these behavioral effects, uncertainty also shapes actors' attitudes about their exchange partners. In particular, previous experimental research fleshes out how uncertainty affects the trust and cohesion that develops between actors of exchange. Similar to commitment, trust can be a method for dealing with uncertainty in exchange transactions. Uncertainty and risk can be important to generating feelings of trust by creating a situation in which partners need to trust one another. As Kollock (1994, p. 319) explains, "the development of high levels of trust requires more than just ongoing interaction. Some level of risk must also be present so that there is a test of trust." Kollock finds the average trustworthiness rating of exchange partners was higher in negotiated exchange conditions with the possibility of exploitation compared to negotiated exchange conditions without this possibility.

Recently, Molm and colleagues have investigated how different forms of exchange affect trust. In a 2000 article, Molm et al. test the prediction that trust is more likely to develop in reciprocal exchange than in negotiated exchange. They argue that the uncertainty of not knowing whether another actor is going to reciprocate has the effect of making reciprocal exchange riskier than negotiated exchange. Greater risk, in turn, makes actors more likely to interpret the behavioral commitments of exchange partners as indicators of trustworthiness in reciprocal exchange. Thus, differences in uncertainty and risk across these two different forms of exchange have consequences for trust.

Cheshire et al. (2010) also examine the relationship between the form of exchange and trust. In their article, they analyze how transitioning from reciprocal exchange to either binding or non-binding negotiated exchange affects trust. They find that transitioning from the high-uncertainty environment of reciprocal exchange to the lower-uncertainty environments of either of the two forms of negotiated exchange resulted in less trust, 
controlling for overall cooperation rates. That is, the findings show that "shifts in the mode of exchange alter participants' trust in their partners" (2010, p. 191) as a result of differences in the amount of uncertainty (and risk) inherent in these different forms of exchange.

Another paper by Molm et al. (2009) inquires as to whether the differences in the amount of trust expressed by exchange partners across reciprocal and negotiated exchange can be eliminated by increasing the amount of risk in negotiated exchange and decreasing the amount of uncertainty in reciprocal exchange. They find that while increasing the amount of risk in negotiated exchange can result in higher levels of trust so long as exchange partners honor agreements, decreasing the uncertainty of reciprocal exchange had relatively little impact. Their research, then, illustrates that trust is affected by uncertainty to the degree that uncertainty introduces risk into the exchange relation.

In addition to trust, social exchange theorists have considered the role of uncertainty in the development of social solidarity and relational cohesion. Molm et al. (2007) examine how the structural characteristics of three different forms of exchange (chain generalized exchange, reciprocal exchange, and negotiated exchange) affect the development of social solidarity. They find that generalized exchange yields higher levels of trust, affective regard and social unity than the other forms of exchange. This is likely due, in part, to the higher level of risk and uncertainty in generalized exchange over whether exchange acts will ultimately be reciprocated. In another study, Molm et al. (2012) examine how the history and embeddedness of the two forms of direct exchange modify the integrative bonds that develop between actors. They show that integrative bonds are higher for negotiated exchange if reciprocal exchange precedes it or if reciprocal exchange is embedded within it. Interestingly, the greater integrative bonds produced by reciprocal exchange are only moderately suppressed by a history or embedding of negotiated exchange. It appears that the bonds that develop in part because of the uncertainty and risk associated with reciprocal exchange are resilient to shifts in exchange form.

Lawler and Yoon (1996) also consider the effects of uncertainty on relational cohesion and find that uncertainty reduction can mediate the effect of exchange frequency on cohesion in negotiated exchange relations. ${ }^{3}$ This is an important finding as perceptions of dyadic cohesion affect whether actors view their exchange networks as being groups and whether they choose to share resources with the members of that network (Thye et al. 2011). Schaeffer and Kornienko's (2009) study of relational cohesion in 3 positively connected networks confirms a relationship between uncertainty and relational cohesion, as it shows the mediating effects of uncertainty for advantaged actors. Interestingly, a similar study of positively connected networks by Lawler et al. (2000) did not find this direct link between uncertainty and relational cohesion, although it did show that uncertainty influenced an actor's likelihood of participating in a risky joint venture. Still, the evidence suggests that effects of uncertainty go beyond influencing whether actors trust exchange partners to inform whether they view exchange relations as cohesive units.

Thus, uncertainty raises the stakes of exchange in ways that foster commitment, trust, social solidarity and relational cohesion among exchange partners, and these elements, in turn, influence other important processes and elements in exchange. For example, Cook and Emerson (1978) find that commitment between dyads in exchange relations reduces power-use by high power actors. Consequently, the level of uncertainty has far-reaching effects in terms of influencing the nature and quality of exchange relationships. 


\section{Conclusion}

Exchange is an important part of social life, affecting not only our ability to procure the resources we want and need, but also shaping the nature of our relationships with others. Inherent in these social exchange relations is uncertainty, whether it stems from the types of resources being exchanged, the form of exchange, or how power is distributed and used in exchange structures. Further, uncertainty in exchange, and any risk it generates, is influential in molding how we interact with others. Uncertainty and risk can lead people to form committed relationships with others, and can even affect how likely others are to trust or to care about the people with which they exchange. Thus, uncertainty filters through the exchange process to affect multiple outcomes, from the types of choices people make to how they view and value exchange partners.

Still, there are many unanswered questions about the role of uncertainty in social exchange and avenues for future research. For instance, Lawler states, "Given the uncertainty built into social exchange contexts, actors face serious, irresolvable information deficits. Such conditions should enhance the emotional reactions when they succeed or fail at using exchange opportunities to deal with these uncertainties" (2001, p. 324). Scholars could test this claim more fully and investigate how uncertainty and risk affect emotional reactions in social exchange. Emotions may affect future exchange behaviors, so understanding how uncertainty and risk elicit particular emotional responses may help researchers better predict subsequent behaviors (Lawler and Thye 2006). Additionally, uncertainty and risk could be important to understanding perceptions of justice in exchange, including actors' emotional reactions to injustices, such as anger or guilt. Lastly, future research could evaluate if and how multiple sources of uncertainty work in concert, such as uncertainty stemming from both the nature of resources and the form of exchange, to drive behaviors toward, and perceptions of, exchange partners. It might be that multiple sources of uncertainty are additive, simply contributing their own share of uncertainty, but it is also possible that they interact in new and surprising ways, either greatly increasing or decreasing each others' effects. For example, while generalized exchange is uncertain, asking for a duplicable resource, like a jump start from strangers, reduces the uncertainty that others will agree to the exchange because it is a resource that is easily provided with few costs to the provider (Schaefer 2009). Given that both the form of exchange and the quality of resources involve differences in uncertainty and risk, it might be of interest to study how combinations of sources of uncertainty affect exchange behaviors.

Working to understand the effects of uncertainty in social exchange might also be important for addressing macro-level problems in society. For example, problems common to generalized exchange, such as free-riding by accepting help from others but not giving to others in need, are similar to the difficulties found in social dilemmas, in which behavior that makes sense for the individual leads to a situation in which, collectively, everyone is worse off (Kollock 1998). One way to increase cooperation among individuals is to increase communication, which not only provides information (reducing uncertainty) but has other effects like potentially reinforcing group identity (Kollock 1998; Messick and Brewer 1983). Additionally, the importance of uncertainty in forming committed relationships in exchange could be applicable to the issue of organizational retention. Employee commitment is relevant to organizations as companies with high employee turnover rates may have higher operating costs, such as due to overtime pay or temporary staffing (Griffeth and Hom 2001). Previous studies have relied on the social exchange perspective to explain employee turnover (e.g., Farrell and Rusbult 1981; Rusbult et al. 1988) but surprisingly, this literature has yet to fully investigate the effects 
of uncertainty on employee commitment. An exception is recent work done by Savage (2012) that argues that the uncertainty associated with receiving a job offer motivates registered nurses to reflect back on their existing exchange relationships. Whether or not this results in nurses forming a group identity with existing coworkers depends in part on their past exchange relationships with co-workers. This is an important finding because group identity affects registered nurses' plans to leave one healthcare organization to begin working for another. Given the real world implications, it could be advantageous to examine the effects of uncertainty and risk in social exchange and to incorporate these ideas when tackling theoretical problems of social consequence.

Clearly, social exchange is a thriving area of social psychological inquiry. This paper has reviewed one element of social exchange: uncertainty. It documents the multiple structural sources of uncertainty in social exchange as well as how uncertainty percolates through the exchange process to influence a number of behavioral and attitudinal outcomes. In so doing, it investigates how uncertainty influences the interactions that constitute social life.

\section{Short Biographies}

Scott V. Savage is an assistant professor at the University of California, Riverside. He specializes in the areas of social psychology, organizations, and social mobility. Many of his projects rely on social psychological concepts and theories to address pressing occupational and organizational concerns. His National Science Foundation funded dissertation research drew on existing social exchange and identity theories to generate a new theory of commitment in social and organizational networks. His publications appear in Research in the Sociology of Health Care and Oxford Bibliographies Online.

Kelly Bergstrand is a Ph.D. candidate at the University of Arizona and specializes in social psychology, social movements and environmental sociology. Her current research applies concepts from Affect Control Theory to social movements to identify mechanisms underlying how issues attract supporters. She has received grants from the National Science Foundation and the Social and Behavioral Sciences Research Institute at the University of Arizona and has a forthcoming entry in The Blackwell Encyclopedia of Social and Political Movements.

\section{Notes}

* Correspondence address: Scott V. Savage, Department of Sociology, 1206 Watkins Halls, University of California, Riverside, Riverside CA 92521, USA. E-mail: scott.savage@ucr.edu

1 Not all exchange theories incorporate uncertainty. James Coleman's (1973) theory of collective action and Michener et al.'s (1977) test of this theory, for instance, assumes perfect information.

2 NET assumes that over a number of negotiation opportunities, profits will near a predicted equilibrium. As such, researchers use data from the final experimental periods when testing their predictions (e.g., Markovsky et al. 1988). Functionally, this depresses uncertainty and makes it a less relevant factor for NET's study of power use.

3 Schaefer (2009) finds a similar relationship. He shows that two intrinsic properties of resources, their transferability and duplicability, affect the frequency of exchange between actors in a network, with less frequent exchanges generating more uncertainty and as a result less relational cohesion.

\section{References}

Bienenstock, E. J. and P. Bonacich. 1993. 'Game Theory Models for Social Exchange Networks: Experimental Results.' Sociological Perspectives 36(2): 117-36. 
Cheshire, C., A. Gerbasi and K. S. Cook. 2010. 'Trust and Transitions in Modes of Exchange.' Social Psychology Quarterly 73(2): 176-95.

Coleman, J. S. 1973. The Mathematics of Collective Action. Chicago, IL: Aldine Publishing Company.

Cook, K. S. and R. M. Emerson. 1978. 'Power, Equity and Commitment in Exchange Networks.' American Sociological Review 43(5): 721-39.

Cook, K. S. and R. M. Emerson. 1984. 'Exchange Networks and the Analysis of Complex Organizations.' Pp. 1-30 in Research in the Sociology of Organizations, edited by S. B. Bacharach and E. J. Lawler, Vol. 3. United Kingdom: JAI Press Inc.

Das, T.K. and B. Tang. 2002. 'Alliance Constellations: A Social Exchange Perspective.' The Academy of Management Review 27(3): 445-56.

Ekeh, P. 1974. Social Exchange Theory: Two Traditions. Princeton, NJ: Princeton University Press.

Emerson, R. M. 1962. 'Power-Dependence Relations.' American Sociological Review 27(1): 31-41.

Emerson, R. M. 1972a. 'Exchange Theory, Part I: A Psychological Basis for Social Exchange.' Pp. 38-57 in Sociological Theories in Progress, edited by J. Berger, M. Zelditch Jr and B. Anderson. Boston: Houghton-Mifflin.

Emerson, R. M. 1972b. 'Exchange Theory, Part II: Exchange Relations and Networks.' Pp. 58-87 in Sociological Theories in Progress, edited by J. Berger, M. Zelditch Jr and B. Anderson. Boston: Houghton-Mifflin,.

Farrell, D. and C. E. Rusbult. 1981. 'Exchange Variables as Predictors of Job Satisfaction, Job Commitment, and Turnover: The Impact of Rewards, Costs, Alternatives, and Investments.' Organizational Behavior and Human Performance 27(1): 78-95.

Griffeth, R. W. and P. W. Hom. 2001. Retaining Valued Employees. Thousand Oaks, CA: Sage Publications.

Hogg, M. A. 2006. 'Social Identity Theory.' Pp. 111-36 in Contemporary Social Psychological Theories, edited by P. J. Burke. Stanford, CA: Stanford University Press.

Homans, G. C. 1974. Social Behavior: Its Elementary Forms, rev. edn. New York, NY: Harcourt Brace Jovanovich.

Kahneman, D., J. L. Knetsch and R. H. Thaler. 1991. 'The Endowment Effect, Loss Aversion, and Status Quo Bias: Anomalies.' Journal of Economic Perspectives 5(1): 193-206.

Kollock, P. 1994. 'The Emergence of Exchange Structures: An Experimental Study of Uncertainty, Commitment, and Trust.' American Journal of Sociology 100(2): 313-45.

Kollock, P. 1998. 'Social Dilemmas: The Anatomy of Cooperation.' Annual Review of Sociology 24: 183-214.

Lawler, E. J. 2001. 'An Affect Theory of Social Exchange.' American Journal of Sociology 107(2): 321-52.

Lawler, E. J. and R. S. Ford. 1995. 'Bargaining and Influence in Conflict Situations.' Pp. 236-56 in Sociological Perspectives on Social Psychology, edited by K. S. Cook, G. A. Fine and J. S. House. Boston: Allyn \& Bacon.

Lawler, E. J., R. S. Ford and M. A. Blegen. 1988. 'Coercive Capabilty in Conflict: A Test of Bilaterall Deterrence versus Conflict Spiral Theory.' Social Psychology Quarterly 51(2): 93-107.

Lawler, E. J., C. Ridgeway and B. Markovsky. 1993. 'Structural Social Psychology and the Micro-Macro Problem.' Sociological Theory 11(3): 268-90.

Lawler, E. J. and S. R. Thye. 2006. 'Social Exchange Theory of Emotions.' Pp. 295-320 in Handbook of the Sociology of Emotions, J. E. Stets and J. H. Turner. United States: Springer.

Lawler, E. J., S. R. Thye and J. Yoon. 2000. 'Emotion and Group Cohesion in Productive Exchange.' Journal of Sociology 106(3): 616-57.

Lawler, E. J. and J. Yoon. 1996. 'Commitment in Exchange Relations: Test of a Theory of Relational Cohesion.' American Sociological Review 61(1): 89-108.

Lovaglia, M. J., J. Skvoretz, D. Willer and B. Markovsky. 1995. 'Negotiated Exchanges in Social Networks.' Social Forces 74(1): 123-55.

Lucas, J., C. W. Younts, M. J. Lovaglia and B. Markovsky. 2001. 'Lines of Power Development in Exchange Networks.' Social Forces 80(1): 185-214.

Markovsky, B., J. Skvoretz, D. Willer, M. J. Lovaglia and J. Erger. 1993. 'The Seeds of Weak Power: An Extension of Network Exchange Theory.' American Sociological Review 58(2): 197-209.

Markovsky, B., D. Willer and T. Patton. 1988. 'Power Relations in Exchange Networks.' American Sociological Review 53(2): 220-36.

Messick, D. M. and M. B. Brewer. 1983. 'Solving Social Dilemmas.' Pp. 11-44 in Review of Personality and Social Psychology Vol.4, edited by L. Wheeler and P. Shaver. Beverly Hills, CA: Sage.

Michener, H. A., E. D. Cohen and A. B. Sorensen. 1977. 'Social Exchange: Predicting Transactional Outcomes in Five-Event, Four-Person Systems.' American Sociological Review 42(3): 522-35.

Molm, L. D. 1994. 'Dependence and Risk: Transforming the Structure of Social Exchange.' Social Psychology Quarterly 57(3): 163-76.

Molm, L. D. 1997. Coercive Power in Social Exchange. USA: Cambridge University Press.

Molm, L. D. 2003. 'In the Eye of the Beholder: Procedural Justice in Social Exchange.' American Sociological Review 68(1): 128-52.

Molm, L. D. 2006. 'The Social Exchange Framework.' Pp. 24-45 in Contemporary Social Psychological Theories, edited by P. J. Burke. Stanford, CA: Stanford University Press. 
Molm, L. D., J. L. Collett and D. R. Schaefer. 2007. 'Building Solidarity through Generalized Exchange: A Theory of Reciprocity.' American Journal of Sociology 113(1): 205-42.

Molm, L. D., D. R. Schaefer and J. L. Collett. 2009. 'Fragile and Resilient Trust: Risk and Uncertainty in Negotiated and Reciprocal Exchange.' Sociological Theory 27(1): 1-32.

Molm, L. D., N. Takahashi and G. Peterson. 2000. 'Risk and Trust in Social Exchange: An Experimental Test of a Classical Proposition.' American Journal of Sociology 105(5): 1396-427.

Molm, L. D., M. M. Whitham and D. Melamed. 2012. 'Forms of Exchange and Integrative Bonds: Effects of History and Embeddedness.' American Sociological Review 77(1): 141-65.

Rice, E. 2002. The Effect of Social Uncertainty in Networks of Social Exchange. PhD thesis. Stanford, California: Stanford University. Retrieved November 27, 2011, from ProQuest Dissertations and Theses Database.

Robinson, D. T. and L. Smith-Lovin. 2006. 'Affect Control Theory.' Pp. 137-64 in Contemporary Social Psychological Theories, edited by P. J. Burke. Stanford, CA: Stanford University Press.

Rusbult, C. E., D. Farrell, G. Rogers and A. G. Mainous III. 1988. 'Impact of Exchange Variables on Exit, Voice, Loyalty, and Neglect: An Integrative Model of Responses to Declining Job Satisfaction.' Academy of Management Journal 31(3): 599-627.

Savage, Scott V. 2012. The Tie That Binds: Exchange and Commitment in the Face of Uncertainty. Ph.D. dissertation, Tucson, Arizona: University of Arizona.

Schaefer, D. R. 2009. 'Resource Variation and the Development of Cohesion in Exchange Networks.' American Sociological Review 74(4): 551-72.

Schaefer, D. R. and O. Kornienko. 2009. 'Building Cohesion in Positively Connected Exchange Networks.' Social Psychology Quarterly 72(4): 384-402.

Thibaut, J. W. and H. H. Kelley. 1959. The Social Psychology of Groups. New York, NY: Wiley.

Thye, S. R., E. J. Lawler and J. Yoon. 2011. 'The Emergence of Embedded Relations and Group Formation in Networks of Competition.' Social Psychology Quarterly 74(4): 387-413.

Tversky, A. and D. Kahneman. 1981. 'The Framing of Decisions and the Psychology of Choice.' Science 211(4481): 453-8.

Tversky, A. and D. Kahneman. 1991. 'Loss Aversion in Riskless Choice: A Reference-Dependent Model.' The Quarterly Journal of Economics 106(4): 1039-61.

Willer, David. 1999. Network Exchange Theory. Westport, CT: Praeger.

Yamagishi, T. and K. S. Cook. 1993. 'Generalized Exchange and Social Dilemmas.' Social Psychology Quarterly 56(4): 235-48.

Yamagishi, T., K. S. Cook and M. Watabe. 1998. 'Uncertainty, Trust, and Commitment Formation in the United States and Japan.' American Journal of Sociology 104(1): 165-94. 